\title{
VASCULAR DISEASES AND ROLE OF NITRIC OXIDE
}

\author{
Kushal Chakraborty ${ }^{1}$, Md. Iqbal Alam², Gausal Azam Khan ${ }^{1 *}$ \\ ${ }^{1}$ Department of Physiology, CMNHS, Fiji School of Medicine, Fiji National University, Suva, Fiji Islands \\ ${ }^{2}$ Department of Physiology, Hamdard Institute of Medical Sciences \& Research, Jamia Hamdard, New Delhi, India
}

Received on: 28.05 .2020

Revised on: 11.06 .2020

Accepted on: 25.06 .2020

\begin{abstract}
Endothelium, the inner-most layers of blood vessels is an active monolayer of cells which has been evolved to become specialized barrier between blood and other structures of the vessel wall. Endothelial cell layer is known to communicate between blood and extravascular tissues and is actively involved in cardiovascular homeostasis. Intact endothelium regulates vascular tone, permeability and maintains non-inflammatory, anti-thrombotic surface. Through its ability to express procoagulants, anticoagulants, vasoconstrictors, vasodilators, cell adhesion molecules and cytokines, the endothelium has emerged as one of the pivotal regulators of haemostasis. Under normal conditions, endothelial cell sustains a vasodilatory, anticoagulant and fibrinolytic state in which coagulation, platelet adhesion as well as leukocyte activation and inflammation are suppressed by continuous release of nitric oxide (NO). Endothelium plays a major role in development of cardiovascular diseases (CVDs). Endothelial cell injuries and resultant endothelial dysfunction (ED) plays a key role in the deployment of CVDs. Therefore, the imbalance of endothelial function due to suppression of anticoagulant molecules like nitric oxide (NO), tissue factor pathway inhibition (TFPI), thrombomodulin etc, and over expression of procoagulant molecules like tissue actor (TF), endothelin-1, von Willebrand factor (vWF), plasminogen activator inhibitor (PAI)-1 secreted by endothelial surface is seen during stress. Several factors like infection, hyperglycaemia, hyperlipidaemia, malignancy, oxidative stress, and aging can interfere with endothelial function. It is widely believed, that ED plays a crucial role in the development of cardiovascular diseases. Also it has been reported to be involved in atherosclerosis, thrombosis, hypertension, diabetes and other vascular conditions. In this article we will specifically highlight and review the role of ED in different vascular conditions.
\end{abstract}

\section{Keywords}

Nitric Oxide, CVDs, hypertension, thrombosis, inflammation, stress..

\section{Introduction}

Vascular endothelium is considered as the largest endocrinal organ in the body which has been shown to have a role in homeostasis in the body by exerting various functions [1]. It is made up of simple squamous epithelial cells that line blood vessels, lymphatic vessels and the heart. The vascular endothelium has a total weight of about $1.5 \mathrm{~kg}$. The endothelium has been recognized as a smart barrier and a key regulator of blood flow in micro and macro vascular circulation [2]. Endothelial function is very important, as it interacts with nearly every system in the body, and selectively supplies nutrients and growth factors to every organ. On the other hand, endothelium is also the recipient of active metabolites and delivers them back to the circulation. Previously, it was believed that, endothelium is an inactive barrier between blood and extravascular tissues. However, recent studies have shown that the vascular endothelium is an active paracrine, endocrine, and autocrine organ, responsible 
for the regulation of vascular tone and the maintenance of vascular homeostasis.

\section{Physiological functions of endothelium}

When immediate surrounding tissues are at basal conditions, the endothelium maintains the vessel homeostasis which favors vessel dilation over vasoconstriction [3]. The endothelium being a dynamic reactive tissue, responds to various intrinsic and/or external stimuli (e.g. shear stress, temperature, transmural pressure, temperature, mental stress, neurohumoral responses, immune response and medications $[2,4]$.

Under physiological condition, endothelial cells maintain basal perfusion which is determined by cardiac output, systemic and local vascular resistance. Endothelial metabolism, which is a key regulator of perfusion, is impaired during several diseases like infection, injury, aging, and inflammation, local, blood flow is the result of vascular relaxation and contraction that is balanced by endothelium derived vasodilatative and vasoconstrictive factors [5]. Among these factors, nitric oxide (NO) stands out as hub and target of many pathways and mechanisms [6]. It is important to understand the biochemical foundations of $\mathrm{NO}$ for endothelial functions. NO, a potent vasodilator, is released from the endothelium due to shear stress. This NO is released by endothelial nitric oxide synthase (eNOS) by utilizing Larginine as substrate which leads to the production of intracellular cyclic GMP (cGMP) [7]. However, in an event when the NO-dependent vasodilation is compromised, the cytochrome-derived factors, natriuretic peptide [8], and prostacyclin [9] dependent vasodilator mechanism comes into action. During diseased state, there is impaired endothelial function and this results in the balance shift towards prevailing constrictive factors and/or downregulation of vasodilatative factors. An important counterweight in the vascular balance is cyclooxygenase (COX). This mostly induces COX-1 which is endogenous, and may involve COX-2 if it is induced. The COXs have a key role in generating vasoconstrictive factors.

The COX enzymes transform arachidonic acid into endoperoxides and further into thromboxane $\mathrm{A}_{2}\left(\mathrm{TXA}_{2}\right)$ [10], prostaglandins and prostacyclin [11]. Local presence of thrombin evokes inducible NO release. Release of serotonin and ADP from platelets in turn increases the NO synthesis and release in healthy endothelium to induce dilatation [12]. When vasodilatory function of endothelium is impaired, then the thrombus formation is mechanically promoted by vasoconstriction via $\mathrm{TXA}_{2}$ and by the direct effect of serotonin on smooth muscle cells [13].

\section{Endothelial Dysfunction}

3.1 Nitric oxide-generation and significance

In last 20 years, world has witnessed a gripping surge in the field of NO biology. NO is a free radical, an endogenous product that was first reported as endothelium-derived relaxing factor (EDRF) by Furchgott and Ignarro in 1986 $[14,15]$. Nitric Oxide (NO) plays a significant role in several pathophysiological conditions such as atherosclerosis, hypertension, angiogenesis-associated disorders, nervous and immune systems, defense mechanisms against infectious diseases and tumors [16-25]. NO is mainly produced from 1arginine by eNOS [26-29]. L-arginine was first discovered and characterized as substrate for NOS for the production of NO [30-32]. Three distinct genes catalyze the production of NO from L-arginine: neuronal NOS (nNOS), inducible NOS (iNOS) and endothelial NOS (eNOS). However, endothelium-derived $\mathrm{NO}$ is a potent vasodilator [33,34]. In the vasculature, NO stimulates sGC to produce cGMP, decreases the intracellular concentration of calcium and causes relaxation of vascular smooth muscle. NO also mediates hypoxic augmentation of contraction in coronary arteries, a response which depends on $\mathrm{sGC}$ but independent of cGMP production (Figure 1) [35].

Traditionally, ED has been associated with pathological conditions that might have altered anticoagulant function, impaired anti-inflammatory properties of the endothelium, impaired modulation of vascular growth, and dysregulation of vascular remodeling. For instances, a plethora of studies has confirmed that the impairment of endothelium-dependent vasorelaxation is caused by a los s of NO bioactivity/availability in the vessel wall [4]. The loss of NO bioavailability is the salient feature of a dysfunctional endothelium, which in turn is the sentinel of systemic or focal vascular disease.

Numerous studies have shown that most of the cardiovascular diseases were initiated from ED. The decline in NO bioavailability may be caused by decreased expression in endothelial cells [36], a lack of substrate or cofactors for eNOS [37], the presence of inhibitor of NOS [38], and alterations of cellular signaling and finally, accelerated NO degradation by reactive oxygen species (ROS) (Figure 1) [39]. Another aspect of ED is impaired endothelial barrier function. Depending on the mode of pathophysiological changes, barrier function may be impaired locally or systemically (Figure 2). Localized loss of the selective barrier function (manifested as edema), coupled with the mobilization of leukocytes, have been recognized as cardinal signs of inflammation [40]. From an immunological point of view, reaction to tissue injury or infection leads to cross-talk between leukocyte and endothelium. However, from the perspective of hemostasis and thrombosis, ED is characterized by activation of pro-inflammatory and procoagulant molecules, as well as the suppression of antiinflammatory, and anti-coagulant molecules. The intact and normal functioning endothelial lining provides a stable 


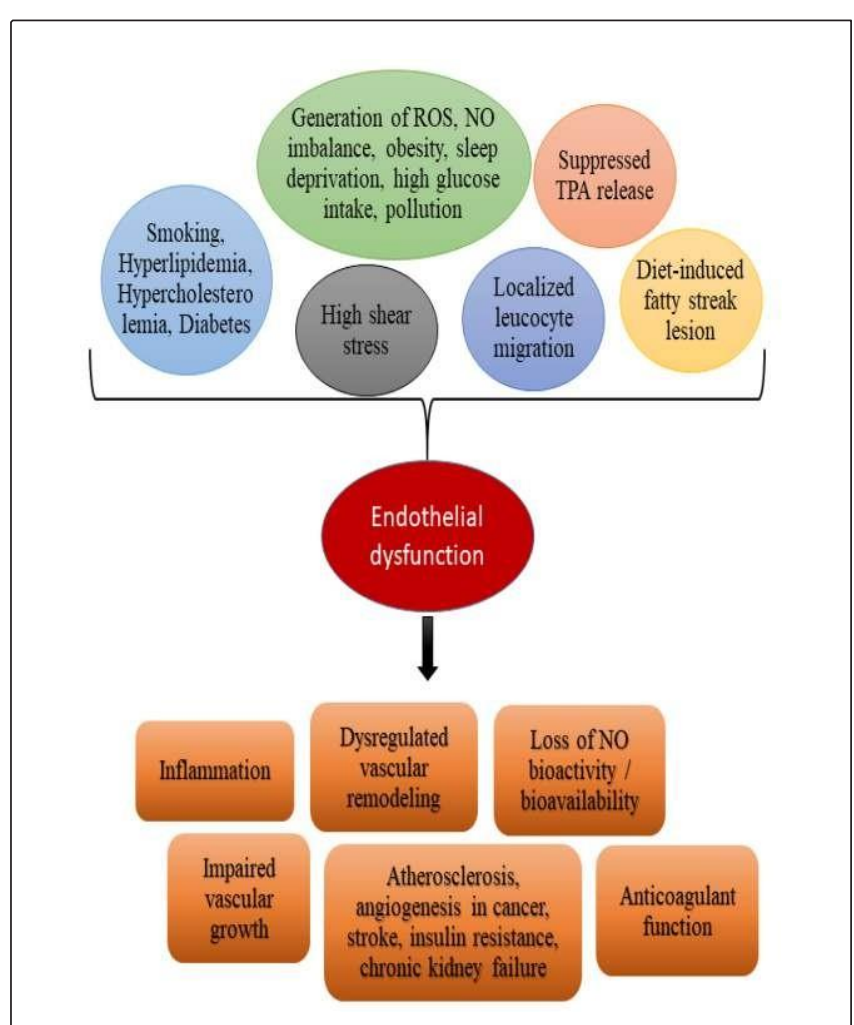

Figure 1: Ischemia-reperfusion induces generation of reactive oxygen species; its role in generation of nitric oxide, coronary vasoconstriction/dilation, causing decreased NO production, followed by impaired endothelium-dependent vasodilation.

reservoir for blood as its luminal surface does not activate the coagulation cascade or promote leukocyte-platelet adhesion, and it also exhibits anticoagulant and fibrinolytic properties (Figure 2) [41]. Systemic endothelial dysfunction may lead to wide spread inflammation, vascular leakage, thrombocytopenia and disseminated intravascular coagulation (DIC). Therefore, localized ED and leukocyte adhesion may lead to venous thrombosis. Other than altered endothelial barrier function, localized ED also leads to tissue factor (TF) induction and increased von Willebrand factor (vWF) release that shifts the homeostatic balance towards the pro-coagulant-pro-inflammatory phenotype (Figure 2) [42]. Intact endothelium releases pro-fibrinolytic molecules like tissue plasminogen activator (TPA) [43], whereas dysfunctional endothelium suppresses TPA release thereby impairing fibrinolytic function of the endothelium [44]. In contrast to venous endothelial cells and microvascular endothelial cells, arterial endothelial cells are surrounded by vascular smooth muscle layer and adventitial layer. Arterial endothelial cells physiologically experience high sheer stress and synthesize ample amount of NO that facilitate vascular relaxation. In the context of atherogenesis, dysfunction of endothelium is mainly characterized by, a loss of anatomical integrity of the intima, as described by the seminal

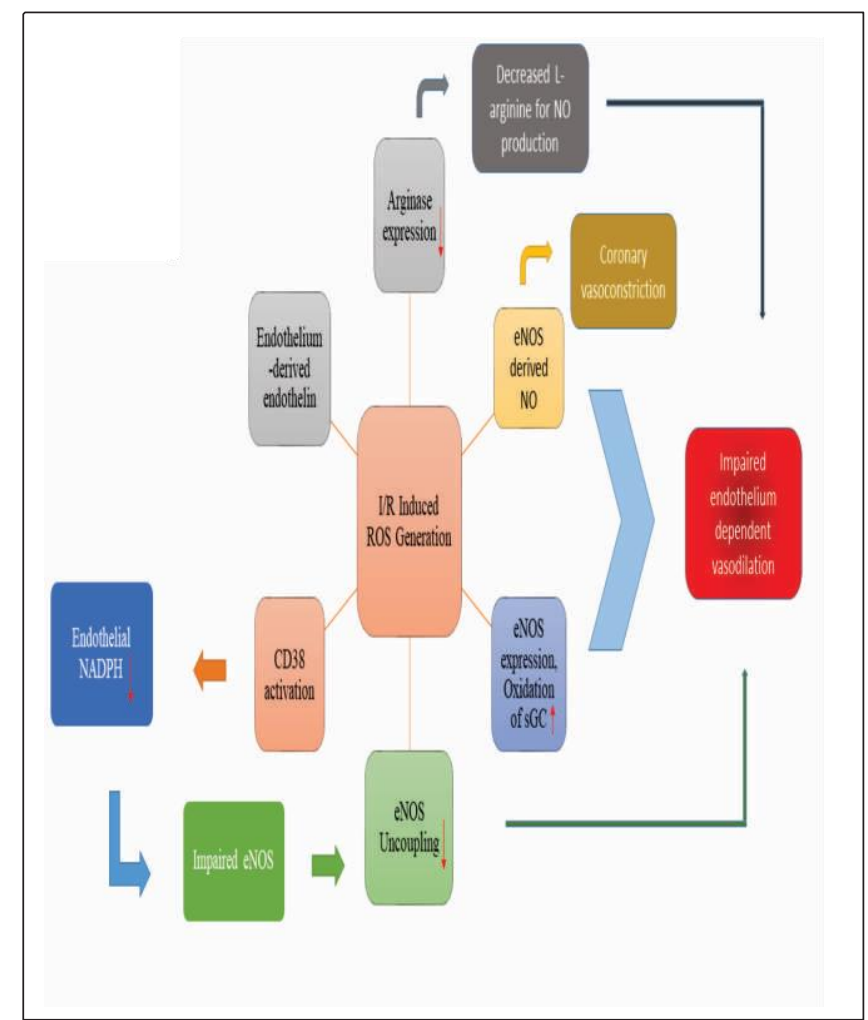

Figure 2: Differential role of endothelial dysfunction cause and effects.

"Response-to-Injury Hypothesis". Endothelial cell injury and subsequent sub-endothelial matrix exposure lead to platelet adhesion and activation through sub-endothelial collagen layer [45]. The initiating event in the atherogenic process is some form of overt injury to the intimal endothelial lining, that is induced by noxious substances (e.g., oxidized cholesterol, cigarette smoke, hyperlipidemia, hypercholesterolemia, hyperglycemia, etc.) or altered hemodynamic sheer stress (e.g., abnormal blood flow caused by hypertension) (Figure 2) [46]. In particular, mechanical tearing of local endothelial is seen as the inciting stimulus for platelets adhesion, activation and the localized release of platelet-derived growth factors (PDGFs). This might then elicit the migration, proliferation and phenotypic modulation of medial smooth muscle cells and thus generate a fibromuscular plaque [47]. It is of great importance to establish the sequential event that lead to the atherogenesis from endothelial injury. But, the direct link between endothelial injury and the genesis of atherosclerotic lesion is still unclear. However, the detailed morphologic examination in diet-induced fatty streak lesions in animal models failed to demonstrate unconcealed intimal injury or platelet adhesion. In this context, it is highly relevant that several molecules including high mobility group protein (HMGB-1) [48], heat 
shock proteins (HSPs) [49] are released from injured endothelium, facilitate monocyte adhesion, a crucial step for plaque formation.

\section{Endothelial dysfunction in atherosclerosis}

$\mathrm{ED}$ of lesion-prone areas of the arterial vasculature lead to atherosclerotic plaque formation [50]. Sequential deterioration of arterial vasculature along with increased sheer stress contribute in lesion formation. ED is one of the early events that are responsible for the deterioration of arterial vasculature [51]. Recent insight into the cellular mechanisms involved in atherogenesis shows that deleterious modifications of endothelial physiology or metabolism is the initial event of vascular remodeling that represents a crucial step in the development of atherosclerosis and are also involved in development of plaque and the occurrence of atherosclerosis [2]. The sequential event including focal permeation, trapping and physicochemical modification of circulating lipoprotein particles in the sub-endothelial space construct an inflammatory lesion [52]. This initiates a coordinated cellular signaling, followed by complex pathogenic sequence and endothelial activation. Activated endothelial cells express several cell adhesion molecules, which facilitate selective recruitment of circulating monocytes from the blood, and invade the tunica intima, where they differentiate into macrophages. These macrophages also abnormally take up modified lipoproteins to become foam cells (the hallmark of early fatty streak lesions [53, 54]. The activated endothelium and macrophages release multiple chemokine, and growth factors which act on neighboring smooth muscle cells (or precursors cell) to induce their proliferation and synthesis of extracellular matrix components within the intimal compartment, thus generating a fibromuscular plaque $[55,56]$. This progressive structural remodeling of developing lesions results in the formation of a fibrous cap, overlying a lipid-rich necrotic core that consists of oxidized lipoproteins, cholesterol crystals and cellular debris. This is also accompanied by varying degrees of matrix remodeling and calcification [57, 58]. The lateral edges of these complicated plaques also contain a rich population of inflammatory cells i.e. activated macrophages, T-lymphocyte, dendritic cells, which secrete several cytokines and chemokines that further activate endothelial pro-inflammatory phenotype, and contribute to structural instability of the plaque through release of proteolytic enzymes (matrix metalloproteases) further leading to modification of sub-endothelial matrix components [59, 60]. Another aspect of atherogenesis is also governed by lipoproteins, mainly through low-density lipoproteins (LDL). This initial arterial remodeling through accumulation of lipids is known as fatty streak formation. The first changes in the arterial wall occur at the branch points of arteries, where adaptive intimal thickening occurs in response to normal hemodynamic stresses [61].
During the early stage of atherogenesis, LDL particles leave the blood and enter the arterial intima, composed of endothelial cells. Accumulation of fat droplets i.e LDL may also occur in the cytoplasm of vascular smooth muscle cells (VSMCs) [58]. LDL particles are then modified by enzymes and are oxidized into highly reactive pro-inflammatory molecule (oxidized LDL), that are recognized by pattern recognition receptors i.e. toll like receptors (TLRs) present in endothelial cells as well as pro-inflammatory macrophages [62]. Oxidized LDL incite the reaction of the innate inflammatory system within the intima and contributes in vascular remodeling. Inflammation begins when activated endothelial cells (through TLRs) express cell adhesion molecules and VSMCs secrete chemokines and chemoattractant, which together draw monocytes, lymphocytes, mast cells, and neutrophils into the arterial wall [63]. Once monocytes enter into the arterial wall through the intima, they become activated into macrophages. These macrophages take up lipids as multiple small inclusions and become transferred into foam cells [56]. The degree of lipid accumulation is critical for early-stage diagnosis of atherosclerosis. Atherosclerosis is believed to start when the lipid accumulation appears as confluent extracellular lipid pools and extracellular lipid cores with decreased cellularity [64]. ED is also responsible for VSMC proliferation and differentiation to myofibroblast. In an intact vessel, VSMCs never come in contact with plasma proteins and therefore devoid of growth factor present in plasma. In physiological condition VSMCs are always maintained in quiescent states. But through early inflammation and endothelial cell activation, VSMCs receive signal from dying cells or growth factors that modify VSMCs to myofibroblast (more proliferative counterpart). Altered VSMCs (myofibroblast) also secrete proteoglycans, collagen and elastic fibers into the sub-endothelial matrix [65]. This transformation of VSMCs further worsens the histological structure and leads to formation of thin-cap fibroatheroma formation [66]. Fibroatheroma can be of two different types depending on the content and stability of the plaque. Stability of the plaque also determines the fate of the fibroatheroma. Unstable fibroatheroma lead to thrombotic plaque formation whereas, stable fibroatheroma accumulate calcium, become stiff and eventually lead to occlusion [66, 67]. Possibility of ruptured plaques may lead to a catastrophic transition into atherosclerotic lesion plaque rupture, with luminal release of the highly thrombogenic contents [68, 69]. Else, some significant clinical sequelae can be seen from superficial intimal erosions, without any indication of plaque rupture [70]. Therefore, an acute transition appears leading to endothelial cell apoptosis, with localized endothelial denudation and thrombus formation leading to obstruction in regional blood flow in later stage $[71,72]$. Whereas, the stable lesions, having thick fibrous cap and less lipid as well as inflammatory cell content, can gradually invade the lumen of 
the vessel causing ischemic symptoms [73,74]. Ruptures of many thin fibrous caps remained clinically silent and are subsequently healed by forming fibrous tissue matrices of cells, collagen fibers, and extracellular space but may rupture again with thrombus formation of the necrotic core, triggering an atherothrombotic occlusion. These cyclic occurrences of rupture, thrombosis, and healing as many as four times at a single site in the arterial wall, results in multiple layers of healed tissue. In these conditions calcium deposition in the wall of the vessels forms micro-aggregates of thrombus, which in turn forms large nodules at later stage. Later on these plaques ruptures and exposes the nodules and becomes sites for thrombus formation [69]. Therefore, the increasing number of plaques itself might be adequate to form significant stenosis which may cause acute ischemic event [75].

Another area of great importance is the role of ROS producing enzymes in atherosclerosis. A number of enzyme systems can produce ROS in the vascular wall. Among them four have gained major attentions in recent years, namely, NADPH oxidase, xanthine oxidase, enzymes of the mitochondrial respiratory chain and especially a dysfunctional endothelial NO synthase (eNOS) [76]. Here in this section we will focus mainly to NADPH oxidase and eNOS. NADPH oxidases are major sources of ROS in the vasculature, producing superoxide from molecular oxygen using NADPH as the electron donor. The oxidases are multisubunit enzyme complexes incorporating one of several homologs of the membrane-bound Nox catalytic subunits $[77,78]$. In the vascular wall, Nox 1 and Nox 4 are expressed in vascular smooth muscle cells whereas Nox 2 and Nox 4 are predominantly found in endothelial cells [79-82]. It is reported that, although an activation of endothelial Nox 2 in other cell types makes an indispensable contribution to progression of atherosclerosis, under physiological conditions, eNOS produces NO, which represents a key element in the vasoprotective function of the endothelium [83-86]. Under pathological conditions associated with oxidative stress, however, eNOS may become dysfunctional [76]. eNOS- derived NO can diffuse from endothelial cells into the underlying smooth muscle cells and induce vasodilation by stimulating NO-sensitive guanylyl cyclase. Endothelial NO can also diffuse into the blood and inhibit platelet aggregation and adhesion [76]. eNOS- derived NO also possesses multiple anti-atherosclerotic properties, including prevention of leucocyte adhesion, migration and vascular smooth muscle cell proliferation through the inhibition of oxidation of LDL [84-86]. Consistent with the anti-atherosclerotic role of eNOS-derived NO, genetic depletion of eNOS leads to accelerated and enhanced atherosclerotic in ApoE-KO mice [87,88]. Uncoupling of eNOS is a crucial mechanism contributing significantly to atherogenesis. It not only reduces NO production, but also potentiates the pre-existing oxidative stress [89]. It has been reported that, the damaging effects of superoxide is produced by uncoupled eNOS-derived NO in atherosclerosis [90].

Based on its multi-regulatory roles throughout this complex series of events, it is evident that ED constitutes a wellcoordinated multicellular pathogenic sequence that lead to atherosclerosis.

\section{Endothelial dysfunction in hypertension}

Millions of people get affected by hypertension leading to worldwide cardiovascular morbidity and mortality and considered as a crucial factor for cardiovascular disease. Hypertension appears to have a complex association with ED, a phenotypical alteration of the vascular endothelium that precedes the development of adverse cardiovascular events. Endothelial cells along with the vascular smooth muscle cells of resistance vessels (arteries and arterioles) regulate hypertension as they continuously constrict and dilate according to the rhythm of cardiac cycle. In response to the blood flow (perfusion), the quiescent healthy endothelium continuously releases potent vasodilators, which have the potential to lower vascular resistance, thereby lowering the blood pressure [91, 92]. In normal condition, basal perfusion is determined by cardiac output, systemic and local resistance. Endothelial cell always maintains a vasodilatory rather than a vasoconstrictive phenotype in an intact healthy vessel. ED is a condition comprising not only of attenuated endothelium-dependent vasodilatation but also an augmented inflammation-induced endothelial activation that leads to vasoconstriction. ED contributes significantly in the development of hypertension, whereas hypertension also leads to endothelial dysfunction. In healthy endothelial tissues, a balance between endothelium-derived relaxing factors (EDRFs) and endothelium-derived contracting factors (EDCFs) is maintained. Endothelium secretes a number of vasodilating factors including $\mathrm{NO}, \mathrm{PGI}_{2}, \mathrm{ET}$ and adenosine. Generation of NO can activate the guanylate cyclase (cGMP) which causes vasodilation through relaxation of vascular smooth muscle cells [93]. Another vasodilatory factor is $\mathrm{PGI}_{2}$, secreted by the endothelium which inhibits platelet aggregation and proliferation of vascular smooth muscle cells [94]. Several vascular contracting factors including: angiotensin-II (Ang-II), endothelin-I (ET-I), dinucleotide uridine adenosine tetraphosphate (UP4A), COX derived $\mathrm{TXA}_{2}$ are also secreted by endothelial cells [95]. Endothelins (ETs) are potent vasoconstrictor molecules having a key role in vascular homeostasis. Although there are three types of ET, vascular ECs mainly produce only ET-1 which has a prominent role in vasoconstriction. Active ET molecule is generated by the actions of an ET converting enzyme (ECE) found on the endothelial cellmembranes. 
There are two types of ET-1 receptors: ET-A and ET-B. Under normal conditions the ET-A receptor is dominant in blood vessels [96]. ET-1 exerts vasoconstriction through activation of dihydropyridine channel (DHP channel) or long lasting $\mathrm{Ca}^{++}$channels (L-type) by binding to ET-A receptors on vascular smooth muscle cells. Smooth muscle cells express both ET-A and ET-B receptors. However, endothelial cells express only ET-B receptors which negatively regulate $\mathrm{NO}$ release. Another vasorelaxing factor adenosine, released from endothelial cells acts through purinergic receptor, helps maintain vascular perfusion [97]. Other than these factors several cytokines and chemokines also play important role in hypertension. Inflammatory cytokine induces generation of reactive oxygen species (ROS), one of the critical factors that link ED and hypertension [98]. It is well established that AngII induces NADPH oxidases (NOX). Recent finding indicates additional source of ROS generation. In small subcutaneous arteries, a significant portion of Ang-II induced ROS is produced by COX-2. In mouse aorta, the mitochondrial monoamine oxidase is another mediator of ROS generation and Ang-II or inflammation induced ED [99]. Therefore, mitochondrial monoamine oxidase- $\mathrm{A}$ and $\mathrm{B}$ are alsoinduced due to $\mathrm{ED}$ in the vessels and generate a significant amount of $\mathrm{H}_{2} \mathrm{O}_{2}$, sufficient to quench endothelial NO. Apart from above, another mitochondrial ROS generating system i.e. p66Shc, also contribute to hypertension-induced ROS production. ROS production is also regulated by several intracellular signaling which further attenuate endothelial dysfunction and hypertension.

\subsection{Endothelial dysfunction in Heart Failure}

Heart failure (HF) is the most common cause of hospitalization in cardiovascular disease with a high mortality rate. Despite novel treatment options for patients suffering from HF, morbidity and mortality rates are still high. With the advancement of medical management, survival of acute coronary disease and cardiac ischemia has been improved. However, in myocardial infarction, prognosis is still poor, as HF with preserved ejection fraction (HFpEF) has a 65\% mortality rate at 5 years. While the heart was an initial focus as the failing "pumping" organ in research and treatment, neurohumoral activation and subsequently the role of a failing endothelium was recognized and investigated in the recent years. Traditionally, HF was recognized as impairment of cardiac muscle activity, known as cardiomyopathy. It has been reported that, altered perfusion in cardiac arteries, due to atherogenesis also contributes to cardiac ischemia and cardiomyopathy.

Reduction in myocardial perfusion due to impaired ventricular function are at least in part, a consequence of reduced endothelium dependent vasodilator capacity of coronary arteries. The prominent regulatory activity of the vascular endothelium in HF was discovered about two decades ago, and its assessment in different cardiovascular disorders, including $\mathrm{HF}$, has been the focus of intense research [100]. On the other hand, declined peripheral vasodilation causes higher systemic and pulmonary vascular resistance, and together with stiffness of conductance arteries, leads to increased afterload. Elevated afterload further increases cardiac workload and therefore worsens the myocardial function. Altered endothelial metabolism further contributes in increasing cardiac afterload [13]. Indeed, various aspects of endothelial function are affected in heart failure, including vasomotor, hemostatic, antioxidant, and anti-inflammatory activities [85, 86]. Differences also exist in the pattern of ED depending on etiology, severity, and stability of HF in individual patients. ED also plays a central role in HF. Heart failure is also characterized by an altered redox state with overproduction of ROS. The increasing evidence suggest that the abnormal cardiac and vascular phenotypes characterizing the failing heart are caused in large part by imbalances between NO bioavailability and oxidative stress [87]. During initial stages of HF, inflammatory mediators from the myocardium, and altered local shear forces modulate gene expression, leukocyte infiltration, increased cytokine production, increased ROS generation and diminished NO bioavailability. Many diverse and often contradictory effects of NO or NO donors on myocardial function have been reported which, until relatively recently, have been difficult to make sense of. However, there is now emerging consensus that NO generally acts to fine tune and optimize cardiac pump function. Studies have shown that, suboptimal doses of NO exert small positive inotropic effects, which may serve to enhance basal cardiac function [101-104]. Augmented data suggests that NO derived both from eNOS from sarcolemmal caveolae and nNOS in the sarcoplasmic reticulum (SR) of the cardiac myocyte may modulate events like calcium influx through sarcolemmal L type channels and the release and re-uptake of calcium by SR $[105,106]$. At physiological doses, NO myocyte relaxation and diastolic function are observed [107-109]. The effects have been confirmed in normal human subjects studied invasively in the catheterization laboratory with intracoronary infusions of the NO donor, sodium nitroprusside, an agonist that releases NO from endothelial cells $[110,111]$. However, there is no direct evidence for deleterious role of NO in human heart failure. The initial speculative suggestions that excessive NO production by iNOS has acute negative ionotropic effects are almost certainly too simplistic. Treatment with NOS inhibitors had no effect on basal function either in myocardial strip preparations or isolated myocytes from end stage failing hearts $[112,113]$. The functional consequences of altered NOS expression and NO bioactivity in the failing human heart are only just beginning to be explored.

Clinical studies showed significant up-regulation of plasma markers of endothelial activation (e.g. E-selectin) and 
endothelial damage (e.g. vWF) in HF [44,85]. However, it is difficult to determine if ED is the cause or effect of the HF. Therefore, HF is regarded as thrombotic complication. As mentioned earlier, during atherogenesis, decreased lumen of cardiac arteries leads to reduced perfusion to the heart muscle. This phenomenon is coupled with increased sheer stress and impaired blood flow. This reduced perfusion either led to ischemia-reperfusion injury or coronary artery thrombosis [85]. Studies showed that ED is one of the principle mediators of ischemia-reperfusion injury and thrombosis. This explains the increased ED markers in coronary artery disease, HF and thrombosis.

\section{Endothelial dysfunction in stroke}

The global burden of neurological diseases including cerebro-vascular stroke has significantly increased, and development of new treatment modalities for cerebrovascular diseases is an urgent need. Cerebrovascular stroke can be broadly subdivided into acute ischemic stroke and hemorrhagic stroke [114]. Acute ischemic stroke is among the leading causes of death and long-term disability. Cerebrovascular stroke in small vessel has functional (lacunar stroke, cognitive impairment, gait and movement disorders) and structural (small subcortical infarct, lacunar infarct, lacunas, white matter lesions, micro bleeds) consequences. In the past few decades the immense development of neuro-radiological methods enabled better imaging of cerebral blood vessels. From the clinical point of view, it is very important to identify the location of vascular lesion. However, the treatment strategies do not depend on the location of vascular impairment. It is now well recognized that ED represents a systemic syndrome involving multiple vascular beds, including the cerebral vasculature [115]. Endothelial function is not uniform throughout the arterial system. It differs between organs and potentially also between different vascular beds within the same organ. Cerebral endothelium is probably one of the most specific types since it is the crucial element of the well-known blood-brain barrier (BBB). The $\mathrm{BBB}$ is a term used to describe the unique properties of the microvasculature of the central nervous system that protects the brain from harmful agents and pathogens [116]. CNS vessels are continuous non-fenestrated vessels, but also contain a series of additional properties that allow them to tightly regulate the movement of molecules, ions, and cells between the blood and the CNS. This heavily restricting barrier capacity allows BBB to tightly regulate CNS homeostasis, which is critical to allow for proper neuronal function, as well as protect the CNS from toxins, pathogens, inflammation, injury, and disease. The cell-to-cell interaction with astrocytes, microglia and neurons mainly play an important role for maintenance of $\mathrm{BBB}$ controlled by endothelial cells and pericytes [117].

However, the integrity of BBB is primarily disrupted due to decrease in endothelial cell -cell junction proteins and the detachment of pericytes from the endothelial membrane in homorganic condition [118]. Cerebral autoregulation maintains constant blood flow $(\mathrm{CBF})$ through the brain in spite of changing mean arterial pressure. Autoregulation of cerebral blood flow consists of mechano-and chemoregulation. The serum level of carbon dioxide $\left(\mathrm{CO}_{2}\right)$ is directly controlled by the chemo-regulation independent of changes in mean arterial pressure [119,120]. However, mechano-regulation depends on transmural pressure gradient and endothelial vasodilatation.

As mentioned in previous section, strokes could be divided in two types: ischemic and hemorrhagic. In both, nitric oxide (NO) plays an important role where inducible NOS (iNOS) and neuronal NOS (nNOS) plays the role of neurotoxic agent and endothelial NOS (eNOS) plays the neuroprotective role in acute ischemic stroke [121]. NO thus produced by iNOS and nNOS exerts its neurotoxic effects by producing nitrites and releasing free radicals which eventually damage the mitochondria and genetic materials [122-125]. On the other hand, NO produced by eNOS exerts the neuroprotective effects through the regulation of vascular bed and peripheral nerve tissue $[126,127]$. It has been reported that, the concentration and distribution of $\mathrm{NO}$ in brain tissue is altered significantly after cerebral ischemia [121]. The neuroprotective role of $\mathrm{NO}$ in middle cerebral artery occlusion (MCAO) model shows that NO mediates the neurovascular protection through the inhibition of serine racemases [128]. The integrity of BBB could also be achieved by regulating NO/caveolin 1/MMP pathway, while reduction in mRNA and protein level of iNOS and nNOS would also provide neuroprotection $[129,130]$. The neurotoxic effects of NO in MCAO exhibits its role by increasing infarct size and cerebral vascular injury [131] and activation of iNOS induced cell apoptosis in a rat model of cerebral ischemia-reperfusion injury [132,133]. NO and peroxides cause microvascular dysfunction and poor prognosis [134]. Hence, NO plays a dual role in hemorrhagic and acute ischemic stroke.

\section{Role of Inflammasomes in endothelial dysfunction} Ample research has showed reactive species-mediated activation of inflammasomes (NLRP3), in sterile inflammatory conditions. Inflammasomes are multi-protein platforms, with a molecular mass of at least $700 \mathrm{kD}$ [135] controlling the activation of caspase- 1 and the cleavage of pro-IL-1 $\beta$, enabling the release of the active mature $17 \mathrm{kD}$ cytokine [136,137]. Caspases are responsible for crucial aspects of inflammation and cell death and can be broadly divided into two classes based on their substrate specificity pro-apoptotic/inflammatory (Figure 3) [138]. Inflammasome complexes assemble upon activation by an appropriate stimulus, leading to the multimerization of the adaptor molecule Adaptor Protein apoptosis-associated speck-like protein containing CARD (ASC) (Figure III). In 


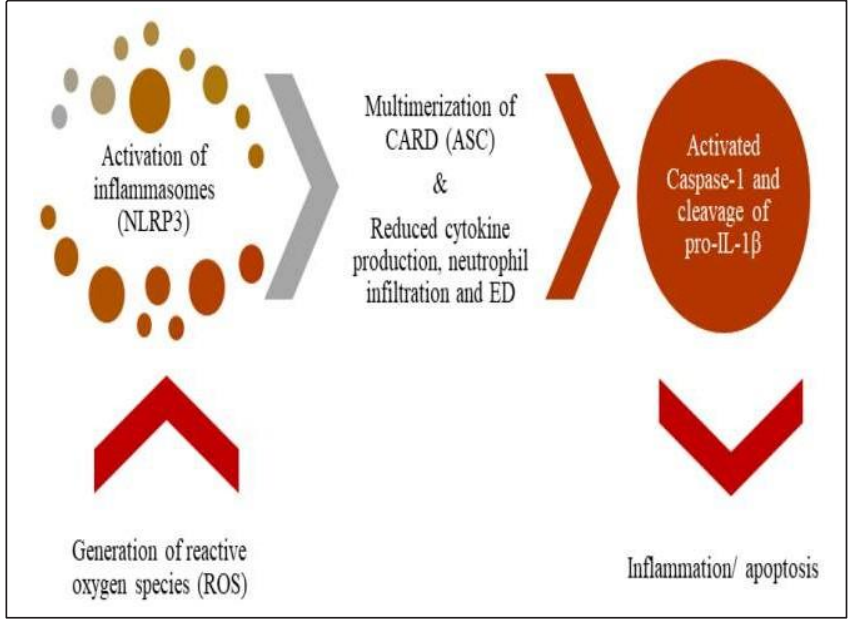

Figure 3: Role of reactive oxygen species on the activation of inflammasome, activation caspase-I, leading to leading to inflammation/apoptosis.

ischemia/reperfusion (I/R), release of ATP and/or mitochondrial DNA following mitochondrial permeability transition pore opening and/or rupture of mitochondrial membranes serve as strong danger signals that initiate sterile inflammation $[139,140]$. Reactive species production by mitochondria also induces detachment of thioredoxin from the potent NLRP3 activator TXNIP in microvascular endothelial cells [141,142]. Postischemic RS production, NLRP3 activation, TXNIP/NLRP3 signaling reduce postischemic cytokine production, neutrophil infiltration, dysfunctional endothelial barrier and cell death $[143,144]$. In postischemic tissues, NLRP3 forms an inflammasome composed of apoptosis-associated Spec-like protein containing a caspase activation and recruitment (ASC), which recruits and activates caspase-1(Figure 3) [145].।

Mounting evidence indicates that inflammation and immune responses play an important role in the overall pathogenesis of ischemic stroke by activating various cascades of damage. Several reports show that ischemic stroke increases the expression and activation of the NLRP3 inflammasome in the neurons and glial cells [146-148]. Several mechanisms trigger NLRP3 inflammasome during cerebral ischemia, acidosis, increased ROS formation, cathepsin release, oxidized mitochondrial DNA, intracellular $\mathrm{Ca}^{2}+$ accumulation, cell swelling, and protein kinase $\mathrm{R}$ (PKR) activation [149-155]. Recent studies have indicated that NO enhances the removal of the dysfunctional mitochondria and prevents assembly of the inflammasome, which leads to downregulation of the NLRP3 inflammasome and NO in myeloid cells of the mice and humans; inhibits the activation of the NLRP3 inflammasome; and consequently prevents ASC pyroptosome formation, caspase- 1 activation and IL-1 $\beta$ secretion (Figure 3) [156-158]. In conclusion, physiological functions of $\mathrm{NO}$ encompass reduction of inflammatory responses and hence plays an important role in neuroprotection after stroke.

5. Endothelial dysfunction - role in preeclampsia Preeclampsia, which is a hypertensive pregnancy disorder affects around $1-5 \%$ pregnant women and is characterized by hypertension, proteinuria, maternal organ dysfunction and uteroplacental dysfunction (Figure 4) [159,160]. Preeclampsia is a major cause of maternal and fetal morbidity and mortality, affects the health of the mother in the years directly following preeclampsia [161]. Women with a history of preeclampsia have a 2.2 times higher risk of developing ischemic heart disease [161]. In preeclampsia, ED is characterized by oxidative stress, angiogenic and vasodilatory imbalance which could be paired with endoplasmic reticulum stress and endothelial cell apoptosis [162] and reactive oxygen species raises the risk for CVD for example hypertension, hypercholesterolemia and diabetes $[163,164]$. In case of endothelial dysfunction, reactive oxygen species stimulate inflammation via the NF-kB pathway and activation of the macrophages in the plaque [164]. Reactive oxygen species induces the activation of proteases and matrix metalloproteinases (MMP), degrades basement membrane which in turn get involved in plaque

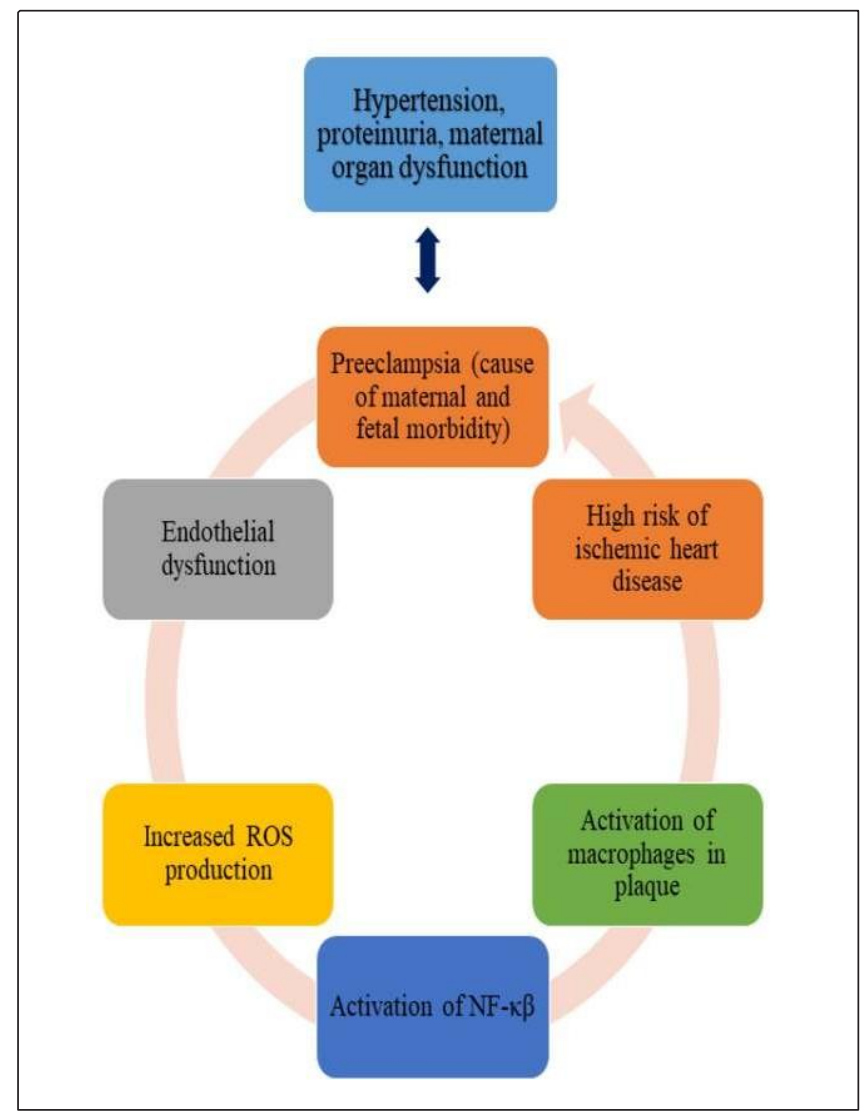

Figure 4: Role of endothelial dysfunction and hypertension in maternal and fetal morbidity during preeclampsia. 
erosion $[165,166]$. Nitric oxide concentration has been shown to have variable results ranging from decreased or increased or even unchanged levels in terms of $\mathrm{NO}$ metabolites in preeclampsia, [167-172]. Although the whole body NO may not change in $\mathrm{PE}$, a reduction in endothelial NO signaling, vascular relaxation in PE and NO bioavailability could be expected [173]. Attempts to assess eNOS activity in $\mathrm{PE}$ led to the conclusion that it is unknown whether eNOS deficiency plays a casual role there. In the murine model, chronic NOS inhibition reversed systemic vasodilation and glomerular hyperfiltration in pregnancy, which suggested its role for endothelial damage and decreased $\mathrm{NO}$ in the pathogenesis of preeclampsia (Figure 4) [174]. Data from PE women is quite limited and without consensus on eNOS expression, as higher, lower and unchanged levels of mRNA or enzyme have been reported $[175,176]$.

\section{Conclusion}

In this review we have tried to focus on the role of ED in CVDs and cardiovascular morbidity where sterile inflammatory responses pose a credible threat, owing to considerable attention.

Patients with chronic inflammatory and / or sterile inflammatory diseases are at high risk for cardiovascular morbidity and mortality. In many inflammatory diseases, this heightened risk of CVDs are reflected in early ED, even in the absence of any other detectable diseases. Several others mechanisms i.e. auto-antibodies, oxidative stress and interactions with traditional risk factors like dyslipidemia and insulin resistance might also be involved. Current literature search provides an insight into the cross-talks between oxidative stress, ED and inflammasomes. Therefore, further research is required to delineate the importance of these processes. The current approaches to diminish cardiovascular morbidity and mortality are focused on controlling traditional modifiable cardiovascular risk factors and reduction of disease risk. Therefore, the precise mechanisms leading to development of CVDs due to inflammation/or sterile inflammation need to be explored. These studies might help to identify unique therapeutic targets to combat these diseases.

The endothelium therefore represents an integrator of vascular risk and the study of its dysfunction may help elucidate mechanisms driving accelerated CVDs in future which could help to develop therapeutic targets for control of CVDs.

\section{Acknowledgement}

This work was supported by grants from the Grand Challenges Canada, Canada, to G.A.K. Madiha Khan, The Heritage School, Kolkata is thanked for English languages correction.

\section{Declaration of conflict of interest: None}

\section{References}

1. Krysko DV, Agostinis P, Krysko O, Garg AD, Bachert C, Lambrecht BN, Vandenabeele P. Emerging role of damage-associated molecular patterns derived from mitochondria in inflammation. Trends Immunol 2011; 32(4): 157-64.

2 Deanfield JE, Halcox JP, Rabelink TJ. Endothelial function and dysfunction: testing and clinical relevance. Circulation 2007 March 13; 115(10): 128595.

3. Widmer RJ, Lerman A. Endothelial dysfunction and cardiovascular disease. Glob Cardiol Sci Pract 2014; 2014(3): 291-308

4. Cai H, Harrison DG. Endothelial dysfunction in cardiovascular diseases: the role of oxidant stress. Circ Res 2000 Nov 10; 87(10): 840-4.

5. Iantorno M, Campia U, Di DN, Nistico S, Forleo GB, Cardillo C, Tesauro M. Obesity, inflammation and endothelial dysfunction. J Biol Regul Homeost Agents 2014April-Jun; 28(2): 169-76.

6. Vallance $\mathbf{P}$, Chan $\mathbf{N}$. Endothelial function and nitric oxide: clinical relevance. Heart 2001; 85(3): 342-50.

7. Zhao Y, Vanhoutte PM, Leung SW. Vascular nitric oxide: Beyond eNOS. J Pharmacol Sci 2015; 129(2): 83-94.

8. Nishikimi T, Maeda N, Matsuoka H. The role of natriuretic peptides in cardioprotection. Cardiovasc Res 2006; 69(2): 318-28.

9. Mitchell JA, Ali F, Bailey L, Moreno L, Harrington LS. Role of nitric oxide and prostacyclin as vasoactive hormones released by the endothelium. Exp Physiol 2008; 93(1):141-7.

10. Smyth EM. Thromboxane and the thromboxane receptor in cardiovascular disease. Clin Lipidol 2010; 5(2): 209-19.

11. Qian H, Luo N, Chi Y. Aging-shifted prostaglandin profile in endothelium as a factor in cardiovascular disorders. J Aging Res 2012; 2012: 121390.

12 Hess CN, Kou R, Johnson RP, Li GK, Michel T. ADP signaling in vascular endothelial cells: ADP-dependent activation of the endothelial isoform of nitric-oxide synthase requires the expression but not the kinase activity of AMP-activated protein kinase. J Biol Chem 2009; 284(47):32209-24.

13. Barthelmes J, Nagele MP, Ludovici V, Ruschitzka F, Sudano I, Flammer AJ. Endothelial dysfunction in cardiovascular disease and Flammer syndromesimilarities and differences. EPMA J 2017; 8(2): 99109. 
14. Furchgott RF: Studies on relaxation of rabbit aorta by sodium nitrite: The basis for the proposal that acidactivable inhibitory factor from bovine retractor penis is inorganic Nitrite and the endothelium-derived relaxing factor is Nitric Oxide. Vasodilation: Vascular smooth muscle peptides, automatic nerves and endothelium. In: P.M. Vanhoutte, Raven Press, New York 1988;401-414.

15. Ignarro LJ, Byrns RE, Wood KS. Biochemical and pharmacological properties of endothelium-derived relaxing factor and its similarity to Nitric Oxide radical. Vasodilation: vascular smooth muscle peptides, automatic nerves and endothelium. In: Vanhoutte PM, Raven Press New York 1988; 427-436.

16. Moncada S, Higgs EA. Nitric oxide and the vascular endothelium. Handb Exp Pharmacol 2006. p213-254.

17. Pacher P, Beckman JS, Liaudet L. Nitric oxide and peroxynitrite in health and disese. Physiol Rev 2007; (87): 315-424.

18. Vanhoutte PM, Shimokawa H, Tang EH, Feletou M. Endothelial dysfunction and vascular dises. Acta Physiol 2009; 196: 193-222.

19. Napoli C, Ignarro LJ . Nitric oxide and atherosclerosis. Nitric Oxide 2001; 5: 88-97.

20. Bredt DS, Hwang PM, Snyder SH. Localization of nitric oxide synthase indicating a neutral role for nitric oxide. Nature 1990; 347: 768-770.

21. Hibbs JB Jr, Taintor RR, Vavrin Z, Rachlin EM. Nitric oxide: a cytotoxic activated macrophage effector molecule. Biochem. Biophysical Res Commun 1988; 8:3-11.

22 Bredt DS, Snyder SH. Nitric oxide, a novel neuronal messenger. Neuron 1992; 8: 3-11.

23. Bogdan C. Nitric oxide and the immune response. Nat Immunol 2001; 2: 907-916.

24. Toda N, Nakanishi-Toda M. How mental stress affects endothelial function. Pfugers Archiv-European J Physiology 2011; 462: 779-794.

25. Toda N, Ayajiki K, Okamura T. Neurogenic and endothelial nitric oxide regulates blood circulation in lingual and other oral tissues. J Cardiovasc Pharmacol 2012; 60:100-108.

26. Chen K, Pittman RN, Popel AS. Nitric oxide in the vasculature: where does it come from and where does it go? A quantative perspective. Antioxidants Redox Signal 2008; 10: 1185-1198.

27. Zweier JL, Samouilov A, Kuppusamy P. Nonenzymatic nitric oxide synthesis in biological systems. Biochim Biophys Acta 1999; 1411: 250-262.
28. Andrew PJ, Mayer B. Enzymatic function of nitric oxide synthases. Cardiovasc Res 1999; 43: 521-531.

29. Zhao Y, Vanhoutte PM, Leung SW. Endothelial nitric oxide sysnthase-independent release of nitric oxide in the aorta of the spontaneously hypertensive rat. J Pharmacol Exp Ther 2013; 344: 15-22.

30. Palmer RM, Ashton D, Moncada S. Vascular endothelial cells synthesize nitric oxide from Larginine. Nature 1988; 333: 664-666.

31. Moncada S, Higgs A. The L-arginine-nitric oxide pathway. N Engl J Med 1993; 329: 2002

32 Schmidt HH, Lkein MM, Niroomand F, Bohme E. Is arginine a physiological precursor of endotheliumderived nitric oxide. Eur J Pharmacol 1988; 148: 293295.

33. Alderton WK, Cooper CE, Knowles RG. Nitric oxide synthases: structure, function and inhibition. Biochem J 2001; 357:593-615

34. Forstermann U, Sessa WC. Nitric oxide synthases: regulation and function. Eur Heart J 2012; 33: 829-837.

35. Zhao Y, Vanhoutte PM, Leung S. Vascular nitric oxide: Beyond eNOS. J Pharmacol Sci 2015; 129: 8394.

36. Cardaropoli S, Silvagno F, Morra E, Pescarmona GP, Todros T. Infectious and inflammatory stimuli decrease endothelial nitric oxide synthase activity in vitro. J Hypertens. 2003; 21(11): 2103-10.

37. Reyes LA, Boslett J, Varadharaj S, De Pascali F, Hemann C, Druhan LJ, Ambrosio G, El-Mahdy M, Zweier JL. Depletion of $\mathrm{NADP}(\mathrm{H})$ due to $\mathrm{CD} 38$ activation triggers endothelial dysfunction in the postischemic heart. Proc Natl Acad Sci U S A 2015; 112(37): 11648-53.

38. Singh B, Biswas I, Garg I, Sugadev R, Singh AK, Dey $\mathrm{S}$, Khan GA. von Willebrand factor antagonizes nitric oxide synthase to promote insulin resistance during hypoxia. Biochemistry 2014; 53(1): 14115-26.

39. Matsubara K, Higaki T, Matsubara Y, Nawa A. Nitric oxide and reactive oxygen species in the pathogenesis of preeclampsia. Int J Mol Sci 2015; 16(3): 4600-14.

40. Chistiakov DA, Orekhov AN, Bobryshev YV. Endothelial Barrier and Its Abnormalities in Cardiovascular Disease. Front Physiol 2015; 6: 365.

41. Reitsma S, Slaaf DW, Vink H, van Zandvoort MA, oude Egbrink MG. The endothelial glycocalyx: composition, functions, and visualization. Pflugers Arch 2007; 454(3): 345-59. 
42 Bonetti PO, Lerman LO, Lerman A. Endothelial dysfunction: a marker of atherosclerotic risk. Arterioscler Thromb Vasc Biol 2003; 23(2): 1168-75.

43. Oliver JJ, Webb DJ, Newby DE. Stimulated tissue plasminogen activator release as a marker of endothelial function in humans. Arterioscler Thromb Vasc Biol 2005; 25(12): 2470-9.

44. Yau JW, Teoh H, Verma $\mathbf{S}$. Endothelial cell control of thrombosis. BMC Cardiovasc Disord 2015; 15: 130.

45. Ruggeri ZM, Mendolicchio GL. Adhesion mechanisms in platelet function. Circ Res 2007; 100(12): 1673-85.

46. Gradinaru D, Borsa C, Ionescu C, Prada GI. Oxidized LDL and NO synthesis--Biomarkers of endothelial dysfunction and ageing. Mech Ageing Dev 2015; 15:1101-13.

47. Badimon L, Padro T, Vilahur G. Atherosclerosis, platelets and thrombosis in acute ischaemic heart disease. Eur Heart J Acute Cardiovasc Care 2012; 1(1): 60-74.

48. Andrassy M, Volz HC, Maack B, Schuessler A, Gitsioudis G, Hofmann N, Laohachewin D, Wienbrandt AR, Kaya Z, Bierhaus A, Giannitsis E, Katus HA, Korosoglou G. HMGB1 is associated with atherosclerotic plaque composition and burden in patients with stable coronary artery disease. PLoS One 2012; 7(12):e52081.

49. $\mathbf{X u} \mathbf{Q}$. Role of heat shock proteins in atherosclerosis. Arterioscler Thromb Vasc Biol 2002; 22(10): 1154759.

50. Virmani R, Kolodgie FD, Burke AP, Farb A, Schwartz SM. Lessons from sudden coronary death: a comprehensive morphological classification scheme for atherosclerotic lesions. Arterioscler Thromb Vasc Biol 2000; 20(5): 1262-75.

51. Davignon J, Ganz P. Role of endothelial dysfunction in atherosclerosis. Circulation 2004; 109(23 Suppl 1): III27-III32.

52 Simionescu N, Vasile E, Lupu F, Popescu G, Simionescu M. Prelesional events in atherogenesis. Accumulation of extracellular cholesterol-rich liposomes in the arterial intima and cardiac valves of the hyperlipidemic rabbit. Am J Pathol 1986; 123(1): 109-25.

53. Ross R. The pathogenesis of atherosclerosis-an update. N Engl J Med 1986; 314(8): 488-500.

54. Ross R. Atherosclerosis-an inflammatory disease. N Engl J Med 1999; 340(2): 115-26.
55. Tabas I, Garcia-Cardena G, Owens GK. Recent insights into the cellular biology of atherosclerosis. J Cell Biol 2015: 209(1): 1313-22.

56. Woollard KJ, Geissmann F. Monocytes in atherosclerosis: subsets and functions. Nat Rev Cardiol 2010; 7(2):77-86.

57. Burke AP, Kolodgie FD, Farb A, Weber D, Virmani R. Morphological predictors of arterial remodeling in coronary atherosclerosis. Circulation 2002; 105(3): 297-303.

58. Guyton JR, Klemp KF. Development of the lipid-rich core in human atherosclerosis. Arterioscler Thromb Vasc Biol 1996; 16(1): 4-11.

59. Tabas I, Lichtman AH. Monocyte-Macrophages and T Cells in Atherosclerosis. Immunity 2017; 47(4): 62134.

60. Johnson JL. Metalloproteinases in atherosclerosis. Eur J Pharmacol 2017; 816: 93-106.

61. Cheng C, Tempel D, van Haperen R, de Boer HC, Segers D, Huisman M, van Zonneveld AJ, Leenen PJ, van der Steen A, Serruys PW, de Crom R, Krams R. Shear stress-induced changes in atherosclerotic plaque composition are modulated by chemokines. J Clin Invest 2007; 117(3): 616-26.

62 Miller YI. Toll-like receptors and atherosclerosis: oxidized LDL as an endogenous Toll-like receptor ligand. Future Cardiol 2005; 1(6): 785-92.

63. Xie C, Ng H, Nagarajan S. OxLDL or TLR2-induced cytokine response is enhanced by oxLDL-independent novel domain on mouse CD36. Immunol Lett 2011; 137(1-2): 3015-27.

64. Pamukcu B, Lip GY, Devitt A, Griffiths H, Shantsila E. The role of monocytes in atherosclerotic coronary artery disease. Ann Med 2010; 42(6): 394-403.

65. Kobiyama K, Ley K. Atherosclerosis. Circ Res 2018; 123(10): 1118-20.

66. Forrester SJ, Kikuchi DS, Hernandes MS, Xu Q, Griendling KK. Reactive Oxygen Species in Metabolic and Inflammatory Signaling. Circ Res 2018; 122(6): 877-902.

67. Basu D, Hu Y, Huggins LA, Mullick AE, Graham MJ, Wietecha T, Barnhart S, Mogul A, Pfeiffer K, Zirlik A, Fisher EA, Bornfeldt KE, Willecke F, Goldberg IJ. Novel Reversible Model of Atherosclerosis and Regression Using Oligonucleotide Regulation of the LDLReceptor. Circ Res 2018; 122(4): 560-7.

68. Mann JM, Davies MJ. Vulnerable plaque. Relation of characteristics to degree of stenosis in human coronary arteries. Circulation 1996; 94(5): 928-31. 
69. Schwartz SM, Galis ZS, Rosenfeld ME, Falk E. Plaque rupture in humans and mice. Arterioscler Thromb Vasc Biol 2007; 27(4): 705-13.

70. Libby $\mathbf{P}$. Mechanisms of acute coronary syndromes. $\mathrm{N}$ Engl J Med 2013; 369(9): 883-4.

71. Quillard T, Araujo HA, Franck G, Shvartz E, Sukhova G, Libby P. TLR2 and neutrophils potentiate endothelial stress, apoptosis and detachment: implications for superficial erosion. Eur Heart J 2015; 36(22): 1394-404.

72 Libby P. How does lipid lowering prevent coronary events? New insights from human imging trials. Eur Heart J 2015; 36(8): 472-4.

73. Back M, Ketelhuth DF, Agewall S. Matrix metalloproteinases in atherothrombosis. Prog Cardiovasc Dis 2010; 52(5): 410-28.

74. Reininger AJ, Bernlochner I, Penz SM, Ravanat C, Smethurst P, Farndale RW, Gachet C, Brandl R, Siess W. A 2-step mechanism of arterial thrombus formation induced by human atherosclerotic plaques. J Am Coll Cardiol 2010; 55(11): 1147-58.

75. Insull W Jr. The pathology of atherosclerosis: plaque development and plaque responses to medical treatment. Am J Med 2009; 122(1 Suppl): S3-S14.

76. Huige L, Horke S, Forsterman U. Vascular oxidative stress, nitric oxide and atherosclerosis. Atherosclerosis 2014; 237:208-219.

77. Drummond GR, Selemidis S, Griendling KK, Sobey CG. Combating oxidatiev stress in vascular disease: NADPH oxidases as therepeutics targets. Nat Rev Drug Discov 2011; 10: 453-471.

78. Bedard K, Krause KH. The NOX family of ROSgenerating NADPH oxidases: physiology and pathophysiology. Physiol Rev 2007; 87: 245-313.

79. Lassegue B, Sorescu D, Szocs K, Yin Q, Akers M, Zhang Y, Grant SL, Lambeth JD, Griendling KK. Novel gp91 (phox) homologues in vascular smooth muscle cells: nox 1 mediates angiotensin II-induced superoxide formation and redox-sensitive signaling pathways. Circ Res 2001; 88: 888-94.

80. Ellmark SH, Dusting GJ, Fui MN, Guzzo-Pernell N, Drummond GR. The contribution of Nox4 to NADPH oxidase activity in mouse vascular smooth muscle. Cardiovasc Res 2005; 65: 495-504.

81. Gorlach A, Brandes RP, Nguyen K, Amidi M, Dehghani F, Busse R. A gp91phox containing NADPH oxidase selectively expressed in endothelial cells is a major source of oxygen radical generation in the arterial wall. Circ Res 2000; 87: 26-32.
82 Ago T, Kitazono T, Ooboshi H, Iyama T, Han YH, Takada J, Wakisaka M, Ibayashi S, Utsumi H, Iida M. Nox4 as the major catalytic component of an endothelial NADPH oxidase. Circulation 2004; 109: 227-33.

83. Sorescu D, Weiss D, Lassegue B, Clempus RE, Szocs K, Sorescu GP, Valppu L, Quinn MT, Lambeth JD, Vega JD, Taylor WR, Griendling KK. Superoxidase production and expression of Nox family proteins in human atherosclerosis. Circulation 2002; 105:1429-35.

84. Li H, Forstermann U. Nitric oxide in the pathogenesis of vascular disease. J Pathol 2000; 109: 244-54.

85. Li H, Forstermann U. Prevention of atherosclerosis by interference with the vascular nitric oxide system. Curr Pharm Des 2009; 15:3133-45.

86. Forstermann U, Sessa WC. Nitric oxide sysnthases: regulation and function. Eur Heart J 2012; 33: 829$837,837 \mathrm{a}-837 \mathrm{~d}$.

87. Kuhlencordt PJ, Gyurko R, Han F, ScherrerCrosbie M, Aretz TH, Hajjar R, Picard MH, Huang PL. Accelerated atherosclerosis, aortic aneurysm formation and ischemic heart disease in apolipoprotein E/endothelial nitric oxide synthase double knockout mice. Circulation 2001; 104: 448-54.

88. Chen J, Kuhlencordt PJ, Astern J, Gyurko R, Huang PL. Hypertension does not account for the accelerated atherosclerosis and development of aneurysms in male apolipoprotein E/endothelial nitric oxide synthase double knockout mice. Circulation 2001; 104:2391-4.

89. Li H, Forstermann U. Uncoupling of endothelial NO synthase in atherosclerosis and vascular disease. Curr Opin Pharmacol 2013; 13: 161-7.

90. Ponnuswamy P, Schrottle A, Ostermeier E, Gruner S, Huang Pl, Ertl G, Hoffmann U, Nieswandt B, Kuhlencordt PJ. eNOS protects from atherosclerosis despite relevant superoxide production by the enzyme in apoE mice. PLoS One 2012; 7: e30193.

91. Brandes RP . Endothelial dysfunction and hypertension. Hypertension 2014; 64(5): 924-8.

92 Bleakley C, Hamilton PK, Pumb R, Harbinson M, McVeigh GE. Endothelial Function in Hypertension: Victim or Culprit? J Clin Hypertens (Greenwich ) 2015; 17(8): 651-4.

93. Munzel T, Daiber A, Ullrich V, Mulsch A. Vascular consequences of endothelial nitric oxide synthase uncoupling for the activity and expression of the soluble guanylyl cyclase and the cGMP-dependent protein kinase. Arterioscler Thromb Vasc Biol 2005; 25(8): 1551-7. 
94. Soler M, Camacho M, Escudero JR, Iniguez MA, Vila L. Human vascular smooth muscle cells but not endothelial cells express prostaglandin E synthase. Circ Res 2000; 87(6): 504-7.

95. Ashton AW, Ware JA. Thromboxane A2 receptor signaling inhibits vascular endothelial growth factorinduced endothelial cell differentiation and migration. Circ Res 2004; 95(4): 372-9.

96. Rodriguez-Vita J, Ruiz-Ortega M, Ruperez M, Esteban V, Sanchez-López E, Plaza JJ, Egido J. Endothelin-1, via ETA receptor and independently of transforming growth factor-beta, increases the connective tissue growth factor in vascular smooth muscle cells. Circ Res 2005; 97(2): 125-34.

97. Bohm F, Ahlborg G, Johansson BL, Hansson LO, Pernow J. Combined endothelin receptor blockade evokes enhanced vasodilatation in patients with atherosclerosis. Arterioscler Thromb Vasc Biol 2002; 22(4): 674-9.

98. Schulz E, Gori T, Munzel T. Oxidative stress and endothelial dysfunction in hypertension, Hypertens Res 2011; 34(6): 665-73.

99. Dikalov SI., Ungvari Z. Role of mitochondrial oxidative stress in hypertension. Am J Physiol Heart Circ Physiol (2013); 305(10): H1417-H1427.

100. Bauersachs J, Widder JD. Endothelial dysfunction in heart failure Pharmacol Rep 2008; 60(1): 119-26.

101. Cotton JM, Kearney MT, Shah AM. Nitric oxide and myocardial function in heart failure: friend or foe? Heart 2002; 88: 564-566.

102 Kojda G, Kottenberg K, Nix P, Schlüter KD, Piper HM, Noack E. Low increase in cGMP induced by organic nitrates and nitrovasodilators improves contarctile response of rat ventricular muscle. Circ Res 1996; 78:91-101.

103. Vila-Petroff MG, Younes A, Egan J, Lakatta EG, Sollott SJ. Activation of distinct cAMP-dependent and cGMP-dependent pathways by nitric oxide in cardiac myocytes. Circ Res 1999; 30: 1215-23.

104. Mohan P, Brutsaert D, Paulus W, Sys SU. Myocardial response to nitric oxide and cGMP. Circulation 1996; 93: 1223-9.

105. Campbell DL, Stamler JS, Strauss HC. Redox modulation of L-type calcium channels in ferret ventricular myocytes. Dual mechanism regulation by nitric oxide and S-nitrosothiols. J Gen Physiol 1996; 108: 277-93.

106. Xu L, Eu JP, Meissner G, Stamler JS et al. Activation of the cardiac calcium release channel (ryanodine receptor) by poly-S-nitrosylation. Science 1998; 279: 234-7.

107. Shah AM, MacCarthy PA. Paracrine and autocrine effects of nitric oxide on myocardial function. Pharmacol Ther 2000; 86: 49-86.

108. Grocott-Mason R, Anning P, Evans H, Lewis MJ, Shah AM et al. Modulation of left ventricular relaxation in isolated ej ecting heart by endogenous nitric oxide. Am J Physiol 1994; 267: H1804-13.

109. Shah AM, Spurgeon HA, Sollot SJ, Talo A, Lakatta EG. 8-bromo cyclic GMP reduces the myofilament response to calcium in intact cardiac myocytes. Circ Res 1994; 74 (5): 970-8.

110. Paulus W, Vantrimont $\mathbf{P}$, Shah A. Acute effects of nitrci oxide on left ventricular relaxation and diastolic distensibility in humans. Circulation 1994; 89: 2070-8.

111. Paulus WJ, Vantrimpont PJ, Shah AM. Paracrine coronary endothelial control of left ventricular function in humans. Circualtion. 1995; 92:2119-26.

112 Drexler H, Kastner S, Strobel A, Studer R, Brodde OE, Hasenfuss G. Expression, activity and functional significance of inducible nitric oxide synthase in the failing human heart. J Am Coll Cardiol 1998; 32: 132-9.

113. Harding SE, Davies CH, Money-Kyrle AM, PooleWilson PA. An inhibitor of nitric oxide synthase does not increase contraction or beta-adrenoreceptor sensitivity of ventricular myocytes from from failing human heart. Cardiovasc Res 1998; 40: 523-9.

114. Mann DL. Inflammatory mediators and the failing heart: past, present, and the foreseeable future. Circ Res 2002; 91(11):988-98.

115. Marti CN, Gheorghiade M, Kalogeropoulos AP, Georgiopoulou VV, Quyyumi AA, Butler J. Endothelial dysfunction, arterial stiffness, and heart failure. J Am Coll Cardiol 2012; 60(16): 1455-69.

116. Andersen KK, Olsen TS, Dehlendorff C, Kammersgaard LP. Hemorrhagic and ischemic strokes compared: stroke severity, mortality, and risk factors. Stroke 2009; 40(6): 2068-72.

117. Ludewig $\mathbf{P}$, Winneberger $\mathbf{J}$, Magnus $\mathbf{T}$. The cerebral endothelial cell as a key regulator of inflammatory processes in sterile inflammation. J Neuroimmunol 2019; 326:38-44.

118. Hawkins BT, Egleton RD. Pathophysiology of the blood-brain barrier: animal models and methods. Curr Top Dev Biol 2008; 80: 277-309.

119. Yang S, Jin H, Zhu Y, Wan Y, Opoku EN, Zhu L, Hu B. Diverse Functions and Mechanisms of Pericytes in Ischemic Stroke. Curr Neuropharmacol 2017; 15(6): 892-905. 
120. Hsu MJ, Hsu CY, Chen BC, Chen MC, Ou G, Lin CH. Apoptosis signal-regulating kinase 1 in amyloid beta peptide-induced cerebral endothelial cell apoptosis. J Neurosci 2007; 27(21): 5719-29.

121. Chen ZQ, Mou RT, Feng DX, Wang Z, Chen G. The role of nitric oxide in stroke. Med Gas Res 2017; 7(3): 194-203.

122 Hirvonen MR, Brune B, Lapetina EG. Heat shock proteinsand macrophage resistance to the toxic effects of nitric oxide. Biochem J 1996; 315: 845-849.

123. Sims NR, Anderson MF. Mitochondrial contributions to issue damage in stroke. Neurochem Int 2002; 40: 511-526.

124. Hämäläinen $M$, Nieminen $R$, Vuorela $P$, Heinonen $M$, Moilanen E. Anti-inflammatory effects of flavonoids: genistein, kaempferol, quercetin, and daidzein inhibit STAT-1 and NF-kappa $\beta$ activations, whereas flavone, isorhamnetin, naringenin and pelargonidin inhibit only NF-kappa $\beta$ activation along with their inhibitory effect on iNOS expression and NO production in activated macrophaages. Mediators Inflamn 2007; 2007: 45673.

125. Zhao X, Haensel C, Araki E, Ross ME, Iadecola $C$. Gene-dosing effect and persistence of reduction in ischemic brain injury in mice lacking inducible nitric oxide synthase. Brain Res 2000; 872: 215-218.

126. Huang Z, Huang PL, Ma J, Meng W, Ayata C, Fishman MC, Moskowitz MA. Enlarged infarcts in endothelial nitric oxide synthase knockout mice are attenuated by nitro-L-arginine. J Cereb Blood Flow Metab 1996; 16: 981-987.

127. Zhang F, Iadecola C. Reduction of focal cerebral ischemic damage by delayed treatment with nitric oxide donors. J Cereb Blood Flow Metab 1994; 14: 574-580.

128. Watanabe A, Sasaki T, Yukami T, Kanki H, Sakaguchi M, Takemori H, Kitagawa K, Mochizuki H. Serine racemase inhibition induces nitric oxide-mediated neurovascular protection during cerebral ischemia. Neuroscience 2016; 339: 139-149.

129. Fu S, Gu Y, Jiang JQ, Chen X, Xu M, Chen X, Shen J. Calycosin-7-O-beta-D-glucoside regulates nitric oxide/caveolin-1/ matrix metalloproteinases pathway and protects blood-brain barrier integrity in experimental cerebral ischemia-reperfusion injury. $\mathrm{J}$ Ethnopahrmacol 2014; 155: 692-701.

130. Yu K, Wu Y, Hu Y, Zhang Q, Xie H, Liu G, Chen Y, Guo $Z$, Jia J. Prior exposure to enriched environment reduces nitric oxide synthase after transient MCAO in rats. Neurotoxicology 2013; 39: 146-152.

131. Mohammadi MT. Overproduction of nitric oxide intensifies brain infarction and cerebrovascular damage through reduction of claudin-5 and ZO-1 expression in striatum of ischemic brain. Pathol Res Pract 2016; 212: 959-964.

132 Zheng L, Ding J, Wang J, Zhou C, Zhang W. Effects and mechanism of action of inducible nitric oxide synthase on apoptosis in a rat model of cerebral ischemia-reperfusion injury. Anat Rec (Hoboken) 2016; 299:246-255.

133. Xu L, Li Y, Fu Q, Ma S. Perillaldehydeattenuates cerebral ischemia-reperfusion injury-triggered overexpression of inflammatory cytokines via modulating Akt/JNK pathway in the rat brain cortex. Biochem Biophys Res Commun 2014; 454: 65-70.

134. Fabian RH, Kent TA. Hyperglycemia accentuates persistent "functional uncoupling" of cerebral microvascular nitric oxide and superoxide following focal ischemia/reperfusion in rats. Transl Stoke Res 2012; 3:482-490.

135. Martinon F, Burns K, Tschopp J. The inflammsome: a molecular platform triggering activation of inflammatory caspases and processing of proIL-beta. Mol Cell 2002; 10: 417-426.

136. Meylan E, Tschopp J, Karin M. Intracellular pattern recognition receptors in the host response. Nature 2006; 442:39-44.

137. Franchi L, Warner N, Viani K, Nuñez G. Function of Nod-like receptors in microbial recognition and host defense. Immunol Rev 2009; 227: 106-128.

138. Siegel RM. Caspases at the crossroads of immune-cell life and death. Nature. Rev Immunol 2006; 6: 308-317.

139. Abais JM, Xia M, Zhang Y, Boini KM, Li PL. Redox regulation of NLRP3 inflammasomes: ROS as trigger or effector? Antioxidants Redox Signal 2015; 22: 11111129.

140. Toldo S, Mezzaroma AG, Mauro F, Salloum BW, Van Tassell BW, Abbate A. The inflammasome in mycardial injury and cardiac remodelling. Antioxidants Redox Signal 2018; 22: 1146-1161.

141. Wen Y, Liu YR, Tang TT, Pan MM, Xu SC, Ma KL, Lv LL, Liu H, Liu BC. mROS TXNIP axis activates Nlrp3 inflammasome to mediate renal injury during ischemic AKI. Int J Biochem Cell Biol 2018; 98: 43-53.

142 Liu D, Xu M, Ding LH, Lv LL, Liu H, Ma KL, Zhang AH, Crowley SD, Liu BC. Activation of the Nlrp3 inflammasome by mitochondrial reactive oxygen species: a novel mechanism of albumin-induced tubulointerstitial inflammation. Int J Biochem Cell Biol 2014; 57:7-19.

143. Cao G, Jiang N, Hu Y, Zhang Y, Wang G, Yin M, Ma X, Zhou K, Qi J, Yu B, Kou J. Ruscogenin attenuates cerebral ischemia-induced blood-brain barrier 
dysfunction by suppressing TXNIP/ Nlrp 3 inflammasome activation and MAPK pathway. Int $\mathrm{J}$ Mol Sci 2016; 17: 1418.

144. Liu Y, Lian K, Zhang L, Wang R, Yi F, Gao C, Xin C, Zhu D, Li Y, Yan W, Xiong L, Gao E, Wang H, Tao L. TXNIP mediates NLRP3 inflammsome activation in cardiac microvascular endothelial cells as a novel mechanism in myocardial ischemia/reperfusion injury. Basic Res Cardiol 2014; 109 (5): 415.

145. Inoue Y, Shirasuna K, Kimura H, Usui F, Kawashima A, Karasawa T, Tago K, Dezaki K, Nishimura S, Sagara J, Noda T, Iwakura Y, Tsutsui H, Taniguchi S, Yanagisawa K, Yada T, Yasuda Y, Takahashi M. NLRP3 regulates neutrophil functions and contributes to hepatic ischemia-reperfusion injury independently of inflammasomes. J Immunol 2014; 192: 4342-4351.

146. Savage CD, Lopez-Castejon G, Denes A, Brough D. NLRP3-inflammasome activating DAMPs stimulate an inflammatory response in glia in the absence of priming which contributes to brain inflammation after injury. Frontier Immunol 2012; 3: 288.

147. Fann DY, Lim YA, Cheng YL, Lok KZ, Chunduri P, Baik SH, Drummond GR, Dheen ST, Sobey CG, Jo DG, Chen CL, Arumugam TV. Evidence that NF- $\kappa$ B and MAPK signaling promotes NLRP inflammasome activation in neurons following ischemic stroke. Mol Neurobiol 2018; 55: 1082-1096.

148. Fann DY, Lee S, Manzanero S, Tang SC, Gelderblom M, Chunduri P, Bernreuther C, Glatzel M, Cheng YL, Thundyil J, Widiapradja A, Lok KZ, Foo SL, Wang YC, Li YI, Drummond GR, Basta M, Magnus T, Jo DG, Mattson MP, Sobey CG, Arumugam TV. Intravenous immunoglibulin suppresses NLRP1 and NLRP3 inflammasome-mediated neuronal death in ischemic stroke. Cell Death Dis 2013; 4: e790.

149. Compan V, Baroja_mazo A, López-Castejón G, Gomez AI, Martínez CM, Angosto D, Montero MT, Herranz AS, Bazán E, Reimers D, Mulero V, Pelegrín P. Cell volume regulation modulates NLRP 3 inflammasome activation. Immunity 2012; 37: 487500 .

150. Lee GS, Subramanian N, Kim AI, Aksentijevich I, Goldbach-Mansky R, Sacks DB, Germain RN, Kastner DL, Chae JJ. The calcium-sensing receptor regulates the NLRP3 inflammasome through $\mathrm{Ca} 2+$ and cAMP. Nature 2012; 492: 123.

151. Liao KC, Mogridge J. Activation of the NLRP1b inflammasome by reduction of cytosolic ATP. Infect Immun 2013; 81: 570-579.

152 Rajamäki K, Nordström T, Nurmi K, Åkerman KE, Kovanen PT, Öörni K, Eklund KK. Extracellular acidosis is a novel danger signal alerting innate immunity via the NLRP3 inflammasome. J Biol Chem 2013; M112: 426254.

153. Zhong Z, Zhai Y, Liang S, Mori Y, Han R, Sutterwala FS, Qiao L. TRPM2 links oxidative stress to NLRP3 inflammasome activation. Nat Commun 2013; 4: 1611.

154. Muñoz-Planillo R, Kuffa P, Martínez-Colón G, Smith BL, Rajendiran TM, Núñez G. K+ efflux is the common trigger of NLRP3 inflammasome activation by bacterial toxins and particulate matter. Immunity 2013; 38:1142-1153.

155. Nakahira K, Haspel JA, Rathinam VA, Lee SJ, Dolinay T, Lam HC, Englert JA, Rabinovitch M, Cernadas M, Kim HP, Fitzgerald KA, Ryter SW, Choi AM. Autophagy proteins regulate innate immune responses by inhibiting the release of mitochondrial DNA mediated by the NALP3 inflammasome. Nature Immunol 2011; 12 (3): 222-30.

156. Chen S, Sun B. Negative regulation of NLRP3 inflammasome signaling. Protein Cell 2013; 4: 251258.

157. Mao K, Chen S, Chen M, Ma Y, Wang Y, Huang B, He Z, Zeng Y, Hu Y, Sun S, Li J, Wu X, Wang X, Strober W, Chen C, Meng G, Sun B. Nitric oxide suppresses NLRP3 inflammasome activation and protects against LPS-induced septic shock. Cell Res 2013; 23: 201.

158. Mishra BB, Rathinam VA, Martens GW, Martinot AJ, Kornfeld H, Fitzgerald KA, Sassetti CM. Nitric oxide controls the immunopathology of tuberculosis by inhibiting NLRP3 inflammasome- dependent processing of IL-1 $\beta$. Nat Immunol 2013; 14: 52.

159. Baumwell S, Karumanchi SA. Pre-eclampsia: clinical manifestations and molecular mechanisms. Nephron Clin Pract 2007; 106: c72-c81.

160. Hernandez-Diaz S, Toh S, Cnattingius S. Risk of preeclampsia in first and subsequent pregnancies: prospective cohort study. Br Med J 2009; 338: b2255.

161. deJager S, Meeuwsen JAL, Pijpen F, Zoet GA, Barendrecht AD, Franx A, Pasterkamp G, van Rijn BB, Goumans MJ, den Ruijter HM. Preeclampsia and coronary plaque erosion: Manifestations of endothelial dysfunction resulting in cardiovascular events in women. Eur J Pharmacol 2017 (Dec 5); 816: 129-137.

162 Hansson GK, Libby P, Tabas I. Inflammation and plaque vulnerability. J Intern Med 2015; 278: 483-493.

163. Harrison D, Griendling KK, Landmesser U,Hornig $\mathbf{B}$, Drexler $\mathbf{H}$. Role of oxidative stress in atherosclerosis. Am J Cardiol 2003; 91: 7A-11A.

164. Li H, Horke S, Forstermann U. Vascular oxidative stress, nitric oxide and atherosclerosis. Atherosclerosis 2014; 237:208-219. 
165. White SJ, Newby AC, Johnson TW. Endothelial erosion of plaques asa substrate for coronary thrombosis. Thromb Haemost 2016; 115: 509-519.

166. Dimmeler S, Haendeler J, Zeiher AM. Regulation of endothelial cell apoptosis in atherothrombosis. Curr Opin Lipidol 2002; 13: 531-536.

167. Choi JW, Im MW, Pai SH. Nitric oxide production increases during normal pregnancy and decreases in preeclampsia. Ann Clin Lab Sci 2002; 32: 257-263.

168. Seligman SP, Buyon JP, Clancy RM, Young BK, Abramson SB. The role of nitric oxide in the pathogenesis of preeclampsia. Am J Obstet Gynecol 1994; 171:944-948.

169. Mutlu-Turkoglu U, Aykac-Toker G, Ibrahimoglu L, Ademoglu E, Uysal M. Plasma nitric oxide metabolites and lipid peroxide levels in preeclamptic pregnant women before and after delivery. Gynecol Obstet Invest 1999; 48: 247-250.

170. Schiessl B, Strasburger C, Bidlingmaier M, Mylonas I, Jeschke U, Kainer F, Friese K. Plasma and urine concentrations of nitrite/nitrate and cyclic Guanosinemono phosphate in intrauterine growth restricted and preeclamptic pregnancies. Arch Gynecol Obstet 2006; 274: 150-154.

171. Pathak N, Sawhney H, Vasishta K, Majumdar S. Estimation of oxidative products of nitric oxide (nitrates, nitrites) in preeclampsia. Aust NZJ Obstet Gynaecol 1999; 39: 484-487.

172 Silver RK, Kupferminc MJ, Russell TL, Adler L, Mullen TA, Caplan MS. et al. Evaluation of nitric oxide as a mediator of severe preeclampsia. Am J Obstet Gynecol 1996; 175 (4 pt 1): 1013-1017.

173. Dymara-Konopka W, Laskowska $M$. The role of nitric oxide, ADMA and homocysteine in the etiopathogenesis of preeclampsia-review. Int J Mol Sci. 2019; 20:2757.

174. Cadnapaphornchai MA, Ohara M, Morris KG, Knotek M, Rogachev B, Ladtkow T, Carter EP, Schrier RW. Chronic NOS inhibition reverses systemic vasodilation and glomerular hyperfiltration in pregnancy. Am J Physiol Ren Physiol 2001; 280: 592598.

175. Laskowska M, Laskowska K, Oleszczuk J. Maternal serum levels of endothelial nitric oxide synthase and ADMA, an endogenous eNOS inhibitor in pregnancies complicated by severe preeclampsia. Pregnancy Hypertens 2012; 2: 312.

176. Laskowska M, Laskowska K, Oleszczuk J. The relation of maternal serum eNOS, NOSTRIN and ADMA levels with aetiopathogenesis of preeclampsia and/or itrauterine fetal growth restriction. J Matern Fetal Neonatal Med 2015; 28: 26-32. 